\title{
Microstructure and thermoelectric properties of
}

\section{hot-extrudedBi-Te-Se bulk materials}

\author{
Zhi-Lei Wang,Takahiro Akao, Tetsuhiko Onda, Zhong-Chun Chen* \\ Department of Mechanical and Aerospace Engineering, Graduate School of \\ Engineering,Tottori University, Koyama-minami 4-101, Tottori 680-8552, Japan
}

\begin{abstract}
Highly dense $n$-type $\mathrm{Bi}_{2} \mathrm{Te}_{2.85} \mathrm{Se}_{0.15}$ bulk thermoelectric materials were fabricated by amechanical alloying (MA) and hot-extrusion technique. The extrusion behavior, microstructure, texture, thermoelectric and mechanical properties have been investigated. The extruded samples exhibited fine-grained microstructure and preferred grain orientation. The basal planes in the extrudates were preferentially oriented parallel to the extrusion direction. As the extrusion temperature increased, the absolute value of theSeebeck coefficient and electrical resistivity were found to decrease, while the thermal conductivity increased. A largest dimensionless figure of merit value of 0.47 was achieved at room temperature for the sample extruded at $400^{\circ} \mathrm{C}$. Moreover, the extruded samples showed high hardness values.
\end{abstract}

Keywords: Bismuth telluride; Thermoelectric materials; Mechanical alloying; Hot extrusion

* Corresponding author.

Tel.: +81857315707 ; fax: +81857315707 .

E-mail address: chen@mech.tottori-u.ac.jp (Z.-C. Chen).

(C) 2015. This manuscript version is made available under the Elsevier user license http://www.elsevier.com/open-access/userlicense/1.0/ 


\section{Introduction}

$\mathrm{Bi}_{2} \mathrm{Te}_{3}$-based compounds, known as the most effectivethermoelectric materials near room temperature, have been widely used in various electronic cooling devices such as infrared detectors, microprocessor chips and thermoelectric coolers for laser diodes [1], owing to fast and precise control of temperature and free of noise during the operations. The conversion efficiency of a thermoelectric device highly depends on dimensionless thermoelectric figure of merit $(Z T)$ of the materials $\left(Z T=\alpha^{2} T /(\rho \kappa)\right.$, where $\alpha, \rho, \kappa$, and Tare the Seebeck coefficient, electrical resistivity, thermal conductivity, and absolute temperature, respectively).

$\mathrm{Bi}_{2} \mathrm{Te}_{3}$ compound has a rhombohedral structure with the atomic layer series in the order of $-\mathrm{Te}(1)-\mathrm{Bi}-\mathrm{Te}(2)-\mathrm{Bi}-\mathrm{Te}(1)$ - along the $c$-axis. This crystalstructureis very easy to cleave on the basal plane due to the existence of the $\mathrm{Te}(1)-\mathrm{Te}(1)$ layer parallel to the basal plane, which is connected by van der Waals bond [2].Moreover, the thermoelectric properties are better in the directions parallel to the basal plane than to the $c$-axis [3].

Currently, $\mathrm{Bi}_{2} \mathrm{Te}_{3}$-based compoundsare mainly fabricated by unidirectional solidification (e.g., zone melting [4] or the Bridgman method [5]) and powder metallurgy (typically, hot-pressing [6]) techniques. The unidirectionally solidified materials present a high $Z T$ value at room temperature, but their mechanical strength is very poor due to large grain sizes and existence of cleavage planes. On the other hand, although hot-pressed materials exhibit high mechanical strength, unfortunately, the thermoelectric performance is not satisfied.Svechnikova et al. [7] reported $Z T \approx 0.93$ 
(250-340K) for $n$-type $\mathrm{Bi}_{2} \mathrm{Te}_{2.85} \mathrm{Se}_{0.15}$ single phase grown by floating-crucibletechnique, but the ingot was brittle with a bending strength $\sigma_{\mathrm{b}}$ of $43 \mathrm{MPa}$.Fan et al. [8] found $Z T \approx$ $0.54(300 \mathrm{~K})$ for $\mathrm{Bi}_{2} \mathrm{Te}_{2.85} \mathrm{Se}_{0.15}$ sample fabricated by mechanical alloying (MA) and plasma activated sintering (PAS) technique.Yang et al. [6] prepared $\mathrm{Bi}_{2} \mathrm{Te}_{2.85} \mathrm{Se}_{0.15}$ compoundwith $0.07 \mathrm{wt} \% \mathrm{SbI}_{3}$ by bulk mechanical alloying (BMA) andhot-pressing $(\mathrm{HP})$ method, obtaining $Z T \approx 0.48$ at room temperature.

The combination ofmechanical alloying (MA) and hot-extrusion isconsidered to be an effective way to fabricate $\mathrm{Bi}_{2} \mathrm{Te}_{3}$-based compounds with oriented fine grains, so as to improve both the thermoelectric and mechanical properties. Recently, our group has fabricated $p$-type $\mathrm{Bi}_{2} \mathrm{Te}_{3}$-based bulk materials by MA and hot-extrusion technique [9], and the results indicated that the extruded materialshave excellent thermoelectric and mechanical performance.

In the present work, the MA and hot-extrusion techniquewas applied to preparation of $n$-type $\mathrm{Bi}_{2} \mathrm{Te}_{3}$-based bulk thermoelectric materials. The purpose was to clarify the effect of some extrusion conditions on extrusion behavior, microstructure, texture, thermoelectric and mechanical properties.

\section{Experimentalprocedure}

High purity $\mathrm{Bi}, \mathrm{Te}$, and Se powders ( $>99.9 \%$ purity) were used as the starting materials. The powders with a nominal composition of $\mathrm{Bi}_{2} \mathrm{Te}_{2.85} \mathrm{Se}_{0.15}$ were pre-mixed in a mortar and pestle, and then mechanically alloyed under $200 \mathrm{rpm}$ for up to $24 \mathrm{hin}$ a purified argon atmosphere using a planetary ball milling system. Subsequently, the 
well reacted powder mixture was pressed into a cylindrical green compact (30 $\mathrm{mm}$ in diameter and $25 \mathrm{~mm}$ in height) by uniaxial pressing, and used as an extrusion billet. Hot extrusion was performed in a temperature range of $340-450^{\circ} \mathrm{C}$ with an extrusion ratio of $25: 1$ at a punch speed of $1 \mathrm{~mm} / \mathrm{min}$.

The density of the extruded samples was determined by the Archimedes method. Phase identification was analyzed by X-ray diffraction (XRD)with $\mathrm{Cu}$ Karadiation. The orientation degree was calculated using theLotgering method by the followingequations [10]:

$f=\frac{P-P_{0}}{1-P_{0}}$

$P_{0}=\frac{\sum I_{0}(00 l)}{\sum I_{0}(h k l)}$

$P=\frac{\sum I(00 l)}{\sum I(h k l)}$

where $f$ is orientation factor; $P_{0}$ and $P$ are the ratios of the integrated intensities of all $(0$ $0 l)$ planes to those of all $(h k l)$ planes for randomly and preferentially oriented samples, respectively.Orientation imaging microscopy (OIM) analysis was performed using a scanning electron microscope (SEM) equipped with an electron backscattered diffraction (EBSD) system.The OIM maps and pole figures were obtained from analysis of the EBSD data by the software TSL-OIM analysis 6.2.The elementalanalysis was carried out by energy dispersive X-ray spectroscopy(EDS).

The electron transport properties were evaluated by a Hall effect measurement system (TOYO Corp., Resi Test 8300). The Seebeck coefficient and electrical resistivity of the samples were simultaneously measured by static DC method and 
four-probe method, respectively, using a thermoelectric property test apparatus (ULVAC-RIKO, ZEM-3). The thermal conductivity was measured by laser flash method (NETZSCH, LFA457 Micro Flash). In the thermal conductivity measurements, the direction of the heat flux was set to the extrusion direction. The dimensionless figure of merit of the samples was calculated by the equation of $Z T=\alpha^{2} T /(\rho \kappa)$. Moreover, the mechanical properties at room temperature were evaluated by the Vickers hardness tests at a load of $1.96 \mathrm{~N}$.

\section{Results and discussion}

\subsection{Preparation of $\mathrm{Bi}_{2} \mathrm{Te}_{2.85} \mathrm{Se}_{0.15}$ alloy powders}

The XRD patterns of the powders as-mixed and MAedwithdifferentmilling timesare shown in Fig. 1. The peaks attributed to the raw powders disappeared and the broadened peaks from $\mathrm{Bi}_{2} \mathrm{Te}_{2.85} \mathrm{Se}_{0.15}$ phaseoccurred instead after MA. When the

milling time reached $8 \mathrm{~h}$, the powdercan be regarded as a single-phase $\mathrm{Bi}_{2} \mathrm{Te}_{2.85} \mathrm{Se}_{0.15}$ solid solution, as shown in Fig. 1(c).The average crystallite sizes calculated by Scherrer equation [11]were $11.30 \mathrm{~nm}, 10.47 \mathrm{~nm}$, and $9.96 \mathrm{~nm}$ for MAed-8h, MAed-12h, and MAed-24h, respectively.There is no significant reduction in crystallitesizewith increasing the milling time.In order to avoid morecontamination and mechanical defects induced by MA, all extruded samples were fabricated by using the powder prepared by MA for $12 \mathrm{~h}$. The morphology of theMAed powder is shown in Fig. 2. Thepowder exhibited fine particles with an average diameterof $<$ $1 \mu \mathrm{m}$. 


\subsection{Extrusion behavior}

Fig. 3 shows the extrusion pressure-stroke curves at different temperatures. In the initial period, the billet is compacted in the container, resulting in a gradual increase in pressure. As the billet is further compacted and flows into the die, the pressure abruptly increases. The extrusion begins at the point where the pressure attains a peak or the pressure gradient starts to relax. In the steady extrusion stage, the pressure change was small. As the extrusion temperature decreased, the pressure level increased,because oflargerdeformation resistance of the billet at a lower temperature.

Fig. 4 shows the appearances of the samples extrudedin a temperature range of $340-450^{\circ} \mathrm{C}$. It is shown that all the samples exhibited sound appearances and no evident defects were observed. Furthermore, all the extrudates had high relative density values of $>98 \%$. It was noted that the surfaces of the extrudatesbecame rough when the extrusion temperature was $>450^{\circ} \mathrm{C}$. Under the conditions used in the present work, dense, crack-free and single phase $\mathrm{Bi}_{2} \mathrm{Te}_{2.85} \mathrm{Se}_{0.15}$ bulk extrudates can be obtained in a temperature range of $340-450^{\circ} \mathrm{C}$.

\subsection{Microstructure and texture}

The OIM maps and corresponding ( $\left.\begin{array}{llll}0 & 0 & 0 & 1\end{array}\right)$ pole figuresat different positions of anextruded sample are shown in Fig. 5,which were measured on the longitudinal section parallel to the extrusion direction. At position "a", where the powder wassubjected to compaction during both cold pressing and subsequent hot extrusion, 
the basal plane $\left(\begin{array}{llll}0 & 0 & 0 & 1\end{array}\right)$ is oriented perpendiculartothe extrusion direction. As the extrusion proceeds, the $\left(\begin{array}{llll}0 & 0 & 0 & 1\end{array}\right)$ pole gradually appears on the equatorial axis of the projection(position "b"). At position "c", a fiber texture is formed, which is parallel to the extrusion direction. These results are in good agreement with the extrusion behavior of $\mathrm{Bi}_{2} \mathrm{Te}_{3}$ compound [12]. After extrusion, the microstructure was characterized by fine and equiaxed grains, and the average grain sizewas measured as $0.54 \mu \mathrm{m}$ (Fig. 5(c)). This is mainly due to the dynamic recrystallization during the extrusion and static recrystallization after the extrusion [12].Theabove results suggest that the basal plane is graduallyrotated from an orientation perpendicular to the extrusiondirection to an orientation parallel to theextrusion direction during the extrusionprocess. This is beneficial to improving the thermoelectric performance of the extruded materials.

Fig. 6 illustrates the XRD patterns measured on the longitudinal and transverse sections of the sample extruded at $360^{\circ} \mathrm{C}$. As a reference, the pattern of as-MAed powder is also included in Fig. 6. The longitudinal section exhibited much stronger diffraction intensities on $\left(\begin{array}{lll}0 & 0 & l\end{array}\right)$ basal planes such as $\left(\begin{array}{lll}0 & 0 & 6\end{array}\right)$ and $\left(\begin{array}{lll}0 & 0 & 15\end{array}\right)$. These results also indicate that the basal planes are preferentially oriented parallel to the extrusion direction after the hot extrusion. Similar results have been confirmed in other samples extruded at different temperatures. The SEM images of the fracture surfaces of the sample extruded at $360^{\circ} \mathrm{C}$ are shown in Fig. 7. Layered and flaky morphologies are observed on the fracture surfaces which are perpendicular and parallel to the extrusion axis, respectively, indicating preferential deformation along the basal planes during 
the hot extrusion. This is in good agreement with the EBSD and XRD results mentioned above.

The OIM maps on the longitudinal sections of the samples extruded at different temperatures are shown in Fig. 8. It was easily found from Fig. 8 and Fig. 5(c) $\left(\mathrm{T}=360^{\circ} \mathrm{C}\right)$ thatthe grains grew up graduallywith the increase in extrusion temperature. The average grain sizes were measured as $0.41 \mu \mathrm{m}, 0.54 \mu \mathrm{m}, 0.75 \mu \mathrm{m}$, and $1.24 \mu \mathrm{m}$ at $340^{\circ} \mathrm{C}, 360^{\circ} \mathrm{C}, 400^{\circ} \mathrm{C}$, and $450^{\circ} \mathrm{C}$, respectively. Accordingly, with the help of mechanical alloying and hot-extrusion processes, fine-grained microstructure with a submicron order can be obtained at extrusion temperatures of $\leq 400^{\circ} \mathrm{C}$. But at $450^{\circ} \mathrm{C}$, some elongated grains are observed as shown in Fig. 8(c). This is probably due to the generation of Te-rich and Te-poor phases which deviate from the nominal composition of $\mathrm{Te}$ in $\mathrm{Bi}_{2} \mathrm{Te}_{2.85} \mathrm{Se}_{0.15}$ compound.

Fig. 9 shows an SEM image of the sample extruded at $450^{\circ} \mathrm{C}$. There are some dark regionswith larger sizes (e.g., " $\mathrm{P}_{1}$ ") and light-grey regions with smaller sizes (e.g., point " $\mathrm{P}_{2}$ "), which are distributed in the matrix. The EDS composition analysis indicated that the Te contentsin the dark and light-grey regions weremuch higher (e.g., 96.83 at $\%$ for point " $\mathrm{P}_{1}$ ") and slightly lower(an average value of $52.01 \mathrm{at} \%$ ) than the nominal composition of $\mathrm{Te}(57 \mathrm{at} \%)$ in $\mathrm{Bi}_{2} \mathrm{Te}_{2.85} \mathrm{Se}_{0.15}$ compound, respectively. Thus, the dark regions can be regarded as a Te-rich phase, which may result from the eutectic reaction occurring when the sample is extruded out of the die at an extrusion temperature of $\geq 413^{\circ} \mathrm{C}$ based on the phase diagram [13]. On the other hand, the light-grey Te-poor phase is considered to be attributed to the sublimation of Te from 
the matrix during the hot extrusion due to a high vapour pressure of $\mathrm{Te}[14]$. The formation of some elongated grains shown in Fig. 8(c) may be associated with the inhomogeneous distribution of the Te-poor phase. For example, a region indicated by an arrow "R" in Fig. 9 showed an elongated morphology, which was surrounded by the Te-poor phase. It should be noted that it is difficult to detect the peaks attributed to Te-rich and Te-poor phases in the XRD patterns, because the former has a small amount and the latter has compositions close to the nominal composition. Detailed formation mechanisms of the Te-rich and Te-poor phases and related microstructure feature will be discussed elsewhere.

The above results of microstructural observationsreveal that the extrudedsamplesshow preferential orientationalong the extrusion direction after the extrusion. The quantitative evaluationof $(00 l)$ orientation in the extruded samples has been conducted according to the Lotgering method [10]. Fig. 10 shows the dependence of the orientation factor $f_{(00 l)}$ on extrusion temperature. The orientation factor gradually increased with increasing the extrusion temperaturebelow $400^{\circ} \mathrm{C}$,but it was slightly reduced at $450^{\circ} \mathrm{C}$.It has been reported that highly oriented textures are easy to form in large grains $[15,16]$. The reason for the decrease in orientation degree at $450^{\circ} \mathrm{Cmay}$ bealso related to the generation of theTe-poor phase as stated above.

\subsection{Thermoelectric and mechanical properties}

Fig. 11 shows the dependence of electron transport properties on extrusion temperature. The carrier concentration gradually increased with increasing the 
extrusion temperature. The Hall mobility exhibitedthe same tendency as the carrier concentration when the extrusion temperature is lower than $400^{\circ} \mathrm{C}$, but it was slightly reduced at $450^{\circ} \mathrm{C}$.

It is well known that carrier concentration ishighlysensitive to chemical composition and lattice defects [17-19]. Navrátiletal. [20] and Zhao et al. [21] have confirmed that the Te vacancies $\left[\mathrm{V}_{\mathrm{Te}}\right]$ can be producedby mechanical treatments such as high-energy ball millingin addition to anti-site defects $\left[\mathrm{Te}_{\mathrm{Bi}}\right]$. Recently, Oh et al. [22] have proposed that the $\left[\mathrm{Te}_{\mathrm{Bi}}\right]$ anti-site defects act as doping defectsvia the following equation:

$T e_{T e}+V_{B i}^{\prime \prime \prime}+3 h^{\bullet} \rightarrow V_{T e}^{\bullet \bullet}+T e_{B i}^{\bullet}+3 e^{\prime}$

where $h^{\bullet}$ is the produced hole; $e^{\prime}$ is the produced electron, which can cause an increasein carrier concentration for $n$-type materials. Due to weak van der Waals bond between $\mathrm{Te}(1)-\mathrm{Te}(1)$ layers, the mechanical deformation during the MA and hot-extrusion processes promotes the formation of Te vacancies $\left[\mathrm{V}_{\mathrm{Te}}\right]$, anti-site defects $\left[\mathrm{Te}_{\mathrm{Bi}}\right]$ and $[\mathrm{e}]$, as expressed in Eq. (4), thus resulting in the increase in carrier concentration.

Ithas been confirmed that the donor-like defects $\left(\left[\mathrm{V}_{\mathrm{Te}}\right]\right.$ and $\left.\left[\mathrm{Te}_{\mathrm{Bi}}\right]\right)$ can be reduced byannealing treatment $[21,23]$.As the extrusion temperature increases, much more donor-like defectsare reduced. This causes ashift of the reactionin Eq. (4)from the left to the right, resulting in anincrease in [e].The mobility parallel to the basal plane is larger than that perpendicular to the basal plane, and it is significantly related 
to orientation degree[24]. Thus, similar dependences of the mobility and orientation factor on extrusion temperature are obtained.

Fig. 12 shows the extrusion temperature dependence of the Seebeck coefficient and electrical resistivityof the hot-extruded samples, measured at room temperature. As the extrusion temperature rose, both theabsolute value of the Seebeck coefficient and electrical resistivity were reduced.The Seebeck coefficient and electrical resistivity are significantly related to electron transport properties. The relationship between the Seebeck coefficient and carrierconcentration can be given by the following equation [25]:

$\alpha \approx \gamma-\ln n$

where $\alpha, \gamma$ and $n$ are the Seebeck coefficient, the scatteringfactor,and the carrier concentration, respectively. Thus, the decreased level of the Seebeck coefficient is mainly due to the increased carrier concentration with increasing the extrusion temperature.

Electricalresistivity depends oncarrier concentration and mobility, and the corresponding relationship can be describedby the following equation:

$$
\rho=\frac{1}{n e \mu}
$$

where $\rho, e$ and $\mu$ are the electrical resistivity, the electron charge, and thecarrier mobility, respectively. From the resultsshown inFig. 11, the decreaseinelectrical resistivity with increasing extrusion temperature is mainly attributed to the increase in 
both carrier concentration and mobility.Moreover, a lower extrusion temperature leads to formation of a fine-grained microstructure, hence resulting in increase in scattering of carriers and thus electrical resistivity.

Fig. 13 shows the dependence of thermal conductivity and figure of merit (ZT)on extrusion temperature. The thermal conductivityincreased with increasingthe extrusion temperature. The thermal conductivity, $\kappa$, is determined by lattice thermal conductivity $\left(\kappa_{p h}\right)$ and electron thermal conductivity $\left(\kappa_{e l}\right)$ [26]:

$\kappa=\kappa_{p h}+\kappa_{e l}$

The lattice $\left(\kappa_{p h}\right)$ and electron $\left(\kappa_{e l}\right)$ thermal conductivities depend on the scattering ofphonons and electrons, respectively. In this work, one of the reasons forincreased thermal conductivity $(\kappa)$ with increasing the extrusion temperatureis grain growth at a higher temperature,which causes the decrease in phonons scattering from grain boundaries and thus increase in thermal conductivity. Another reason is the increased carrier concentration, which leads to the increase in $\kappa_{e l}$.

As a result, a largest $Z T$ value of 0.47 was obtained at room temperature for the sample extruded at $400^{\circ} \mathrm{C}$. This $Z T$ value is almost the same as thoseof the samples fabricated by MA-PAS [8] and BMA-HP [6] methods, and much lower than that prepared by floating-crucibletechnique [7], as mentioned before. Nevertheless, the extruded samples exhibited grain refinement and preferred orientation, which are beneficial to thermoelectric and mechanical performance. Moreover, in our previous research [9], a $Z T$ value of 1.2 was obtained in $p$-type $\mathrm{Bi}_{2} \mathrm{Te}_{3}$-based bulk samples 
preparedby MA and hot-extrusion technique.Consequently, MA and hot-extrusion technique is a potential route to fabricate $\mathrm{Bi}_{2} \mathrm{Te}_{3}$-basedmaterials with good thermoelectric performance. But optimization of the MA and extrusion conditions as well as addition of dopants are necessary to further improve the thermoelectric performance.

Fig. 14 shows the Vickers hardness as a function of extrusion temperature. The hardness monotonically decreased with increasing the extrusion temperature. The reason for this tendency is that a lower extrusion temperature results in a smaller average grain size. The Vickers hardness of the sample extruded at $340^{\circ} \mathrm{C}$ showed 1.5 times higher than that extruded at $450^{\circ} \mathrm{C}$.

\section{Conclusions}

Sound and dense $n$-type $\mathrm{Bi}_{2} \mathrm{Te}_{2.85} \mathrm{Se}_{0.15}$ bulk thermoelectric materials have been successfully fabricated by mechanical alloying and hot-extrusion technique. The combination of mechanical alloying and hot extrusion resulted in significant grain refinement and preferential orientation. Fine-grained microstructure with a submicron order was obtained at extrusion temperatures of $\leq 400^{\circ} \mathrm{C}$. The basal planes in the extrudates were preferentially oriented parallel to the extrusion direction.

The carrier mobility was found to be related to the orientation degree of the basal planes. As the extrusion temperature increased, carrier concentration and thermal conductivity increased, whereas the absolute value of the Seebeck coefficient and electrical resistivity decreased. A largest dimensionless figure of merit value of 0.47 
was achieved at room temperature for the sample extruded at $400^{\circ} \mathrm{C}$. Furthermore, although the Vickers hardness was reduced with increasing the extrusion temperature due to grain growth, all the extruded samples exhibited high hardness values.

\section{Acknowledgements}

The authors would like to thank Profs.ShigekazuMorito and Hiroyuki Kitagawa of Shimane University for their experimental supports and fruitful discussion. This work was supported in part by Japan Science and Technology Agency and the Amada Foundation. 


\section{References}

[1] J.T. Im, K.T.Hartwig,J.Sharp,Acta Mater. 52 (2004) 49-55.

[2] J.R.Weise,L.Muller,J. Phys. Chem. Solids 15 (1960) 13.

[3] L. G.Schulz,J. Appl. Phys.20 (1949)1030.

[4] P. J.Taylor,J. R. Maddux, W. A.Jesser, F. D.Rosi, J. Appl. Phys. 85 (1999) 7807-7813.

[5] W. M.Yim, F. D.Rosi, Solid-State Electron.15 (1972) 1121.

[6] J.Y.Yang, T.Aizawa, A.Yamamoto, T.Ohtab, J. Alloys Compd. 312 (2000) 326-330.

[7] T. E. Svechnikova, P. P. Konstantinov, G. T. Alekseeva, Inorg. Mater. 36 (6) (2000) 556-560.

[8] X. A. Fan, J. Y. Yang, W. Zhu, H. S. Yun, R. G. Chen, S. Q. Bao, X. K. Duan, J. Alloys Compd. 420 (2006) 256-259.

[9] Y.Nagami, K.Matsuoka, T.Akao, T.Onda, T.Hayashi, Z. C.Chen, J. Electron. Mater. 43 (2014)2262-2268.

[10] F. K.Lotgering, J. Inorg. Chem. 9 (1959) 113-123.

[11] P.Scherrer,Mathematisch-physikalischeKlasse (1918)98-100.

[12] Z. C.Chen,K. Suzuki, S.Miura, K.Nishimura,K.Ikeda, Mater. Sci. Eng., A500 (2009)70-78.

[13] A.Brown, B.Lewis,J. Phys. Chem. Solids23(1962)1597-1604.

[14] Y. Suga, Thermoelectric semiconductor, Makisyoten, Tokyo, 1966. 
[15] K. Fukuda, H. Imaizumi, T. Ishii, F. Toyoda, M. Yamanashi, Y. Kibayashi,Proc. 15th Inter. Conf. on Thermoelec. 1996, p. 37.

[16] J. Jiang, L.D. Chen, S.Q. Bai, Q. Yao, Q. Wang, Mater. Sci. Eng., B 117(2005) 334.

[17] T.S. Oh, D.B. Hyum, N.V. Kolomoets, Scripta Mater. 42 (2000) 849-854.

[18] D.M. Lee, C.H. Lim, D.C. Cho, Y.S. Lee, C.H. Lee, J. Electron. Mater. 35(2006) $360-365$.

[19] J.M. Schultz, J.P.Mchugh,W.A.Tiller, J. Appl. Phys. 33 (1962) 2443-2450.

[20] J. Navrátil, Z. Starý, T. Plecháček, Mater. Res. Bull. 31 (1996) 1559-1566.

[21] L. D. Zhao, B. P. Zhang, W. S. Liu, H. L. Zhang, J. F.Li, J. Alloys Compd. 467(2009)91-97.

[22] M. W.Oh, J. H. Son, B. S.Kim, S. D. Park, B. K. Min,H. W.Lee, J. Appl. Phys. $115(13)(2014) .133706$.

[23] J.M. Schultz, J.P. Mchugh, W.A. Tiller, J. Appl. Phys. 33 (1962) 2443.

[24] W.E. Bies, R.J. Radtke, H. Ehrenreich, E. Runge, Phys. Rev. B 65 (2002)085208.

[25] X.D. Liu, Y.H. Park, Mater.Trans. 43 (2003) 681.

[26] T.S. Kim, I.S. Kim, T.K. Kim, S.J. Hong, B.S. Chun, Mater. Sci. Eng., B 90 (2002) 42-46. 


\section{Figure captions}

Fig. 1. XRD patterns of (a) as-mixed, (b) MAed-4h, (c) MAed-8h, (d) MAed-12h, and (e) MAed-24h powders.

Fig. 2. SEM image of $\mathrm{Bi}_{2} \mathrm{Te}_{2.85} \mathrm{Se}_{0.15}$ powder MAed for $12 \mathrm{~h}$.

Fig. 3. Extrusion pressure-stroke curves at different temperatures.

Fig. 4. Appearances of the samples extruded at (a) $340^{\circ} \mathrm{C}$, (b) $360^{\circ} \mathrm{C}$, (c) $400^{\circ} \mathrm{C}$, and (d) $450^{\circ} \mathrm{C}$.

Fig. 5. OIM maps and ( $\left.\begin{array}{llll}0 & 0 & 0 & 1\end{array}\right)$ pole figures on longitudinal section at different positions of the sample extruded at $360^{\circ} \mathrm{C}(\mathrm{ED}$ : extrusion direction and $\mathrm{TD}$ : transverse direction).

Fig. 6. XRD patterns on the longitudinal and transverse sections of the sample hot-extruded at $360^{\circ} \mathrm{C}$.

Fig. 7. SEM images of the fracture surfaces, (a) perpendicular and (b) parallel to the extrusion axis.

Fig. 8. OIM maps on the longitudinal sections of the samples extruded at (a) $340^{\circ} \mathrm{C}$, (b) $400^{\circ} \mathrm{C}$, and (c) $450^{\circ} \mathrm{C}$.

Fig. 9. SEM image of the sample extruded at $450^{\circ} \mathrm{C}$.

Fig. 10. Dependence of orientation factor $f_{(001)}$ on extrusion temperature.

Fig. 11. Dependence of electron transport properties on extrusion temperature.

Fig. 12. Dependences of the Seebeck coefficient and electrical resistivity on extrusion temperature.

Fig. 13. Dependence of thermal conductivity and figure of merit $(Z T)$ on extrusion 
temperature.

Fig. 14. Dependence of Vickers hardness on extrusion temperature. 
Figure 1

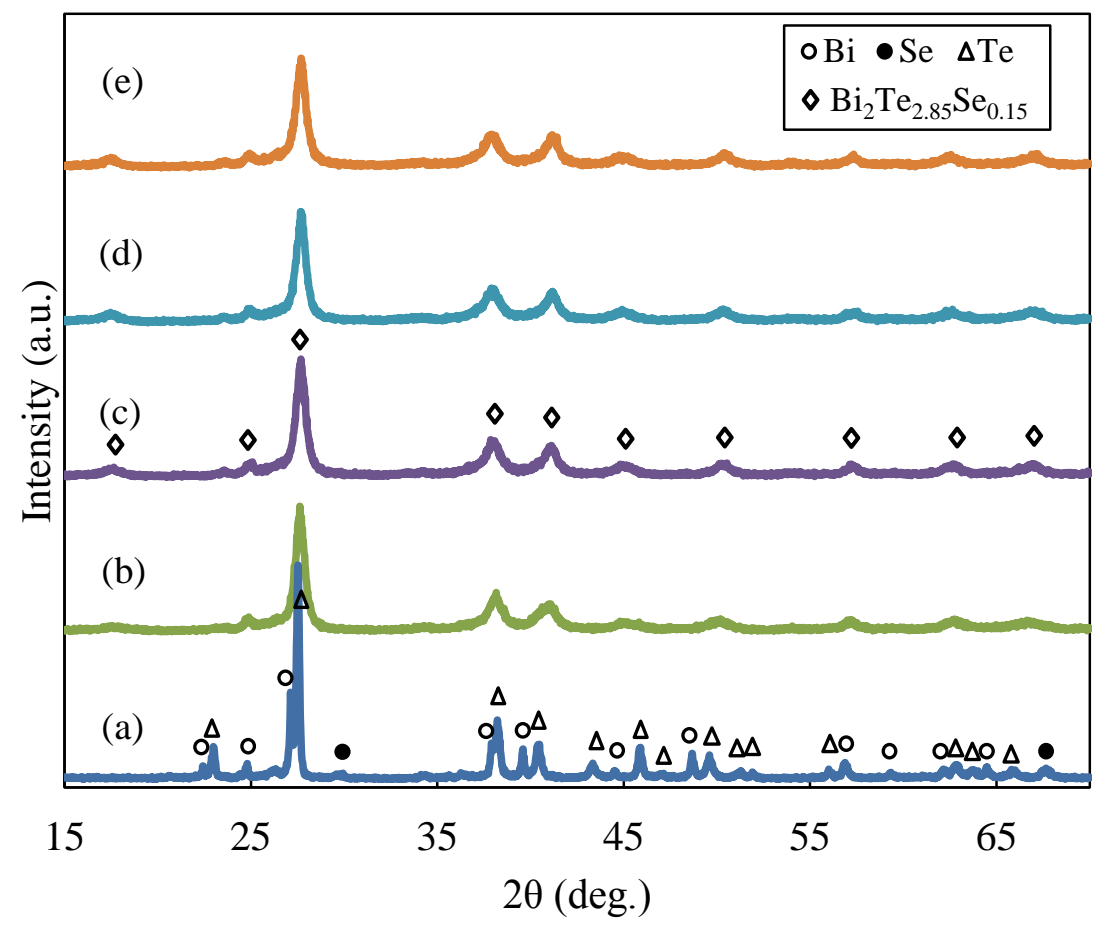




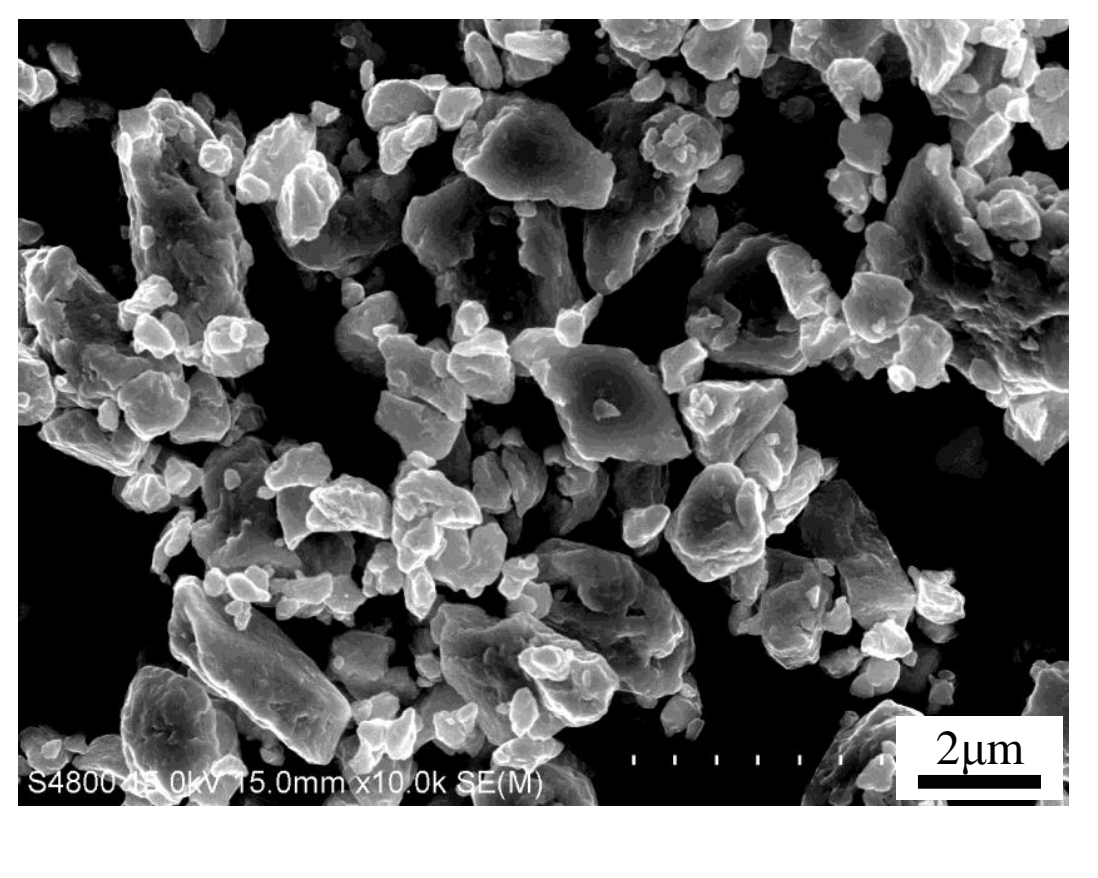

Figure 2
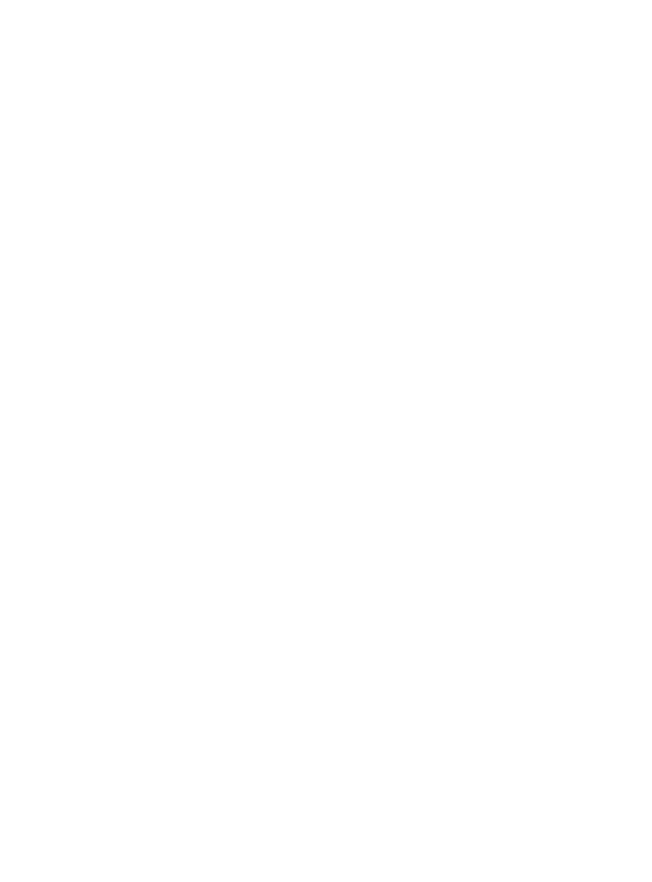
Figure 3

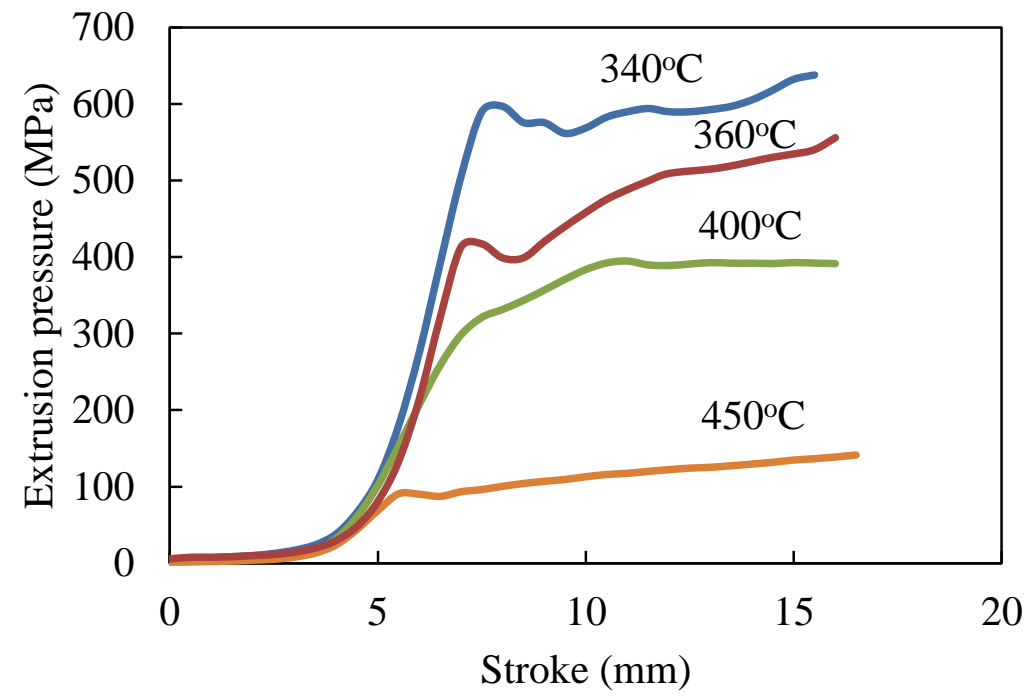


(d)

(c)

(b)

(a)

$10 \mathrm{~mm}$

Figure

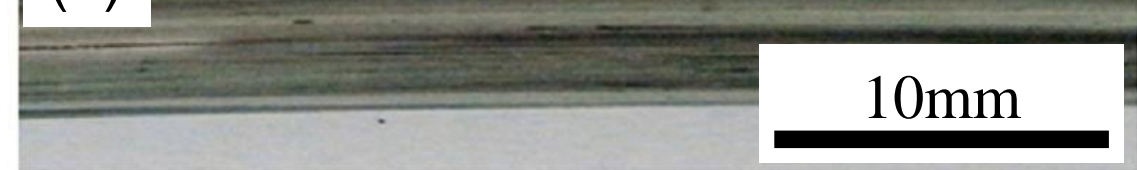


Figure 5
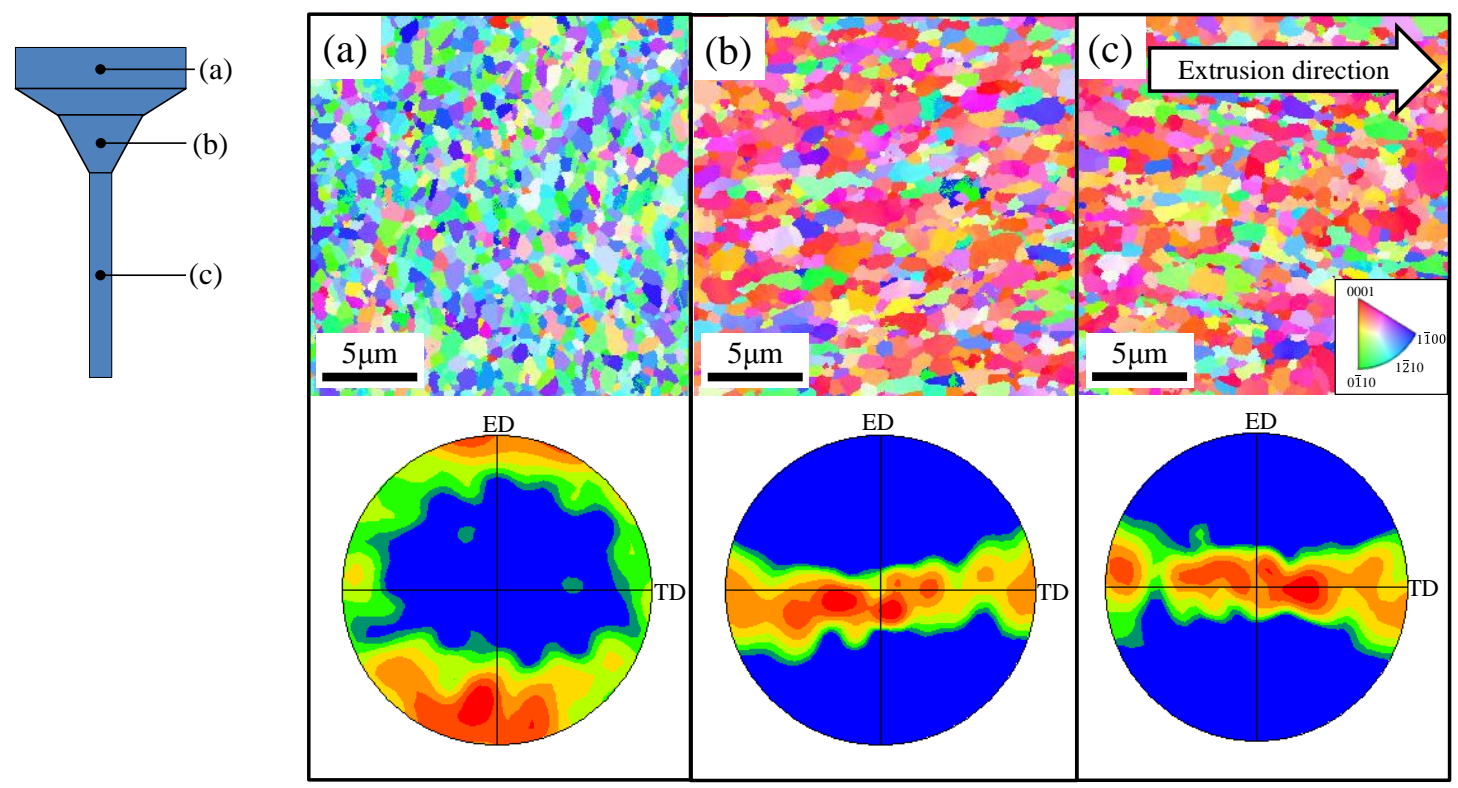
Figure 6

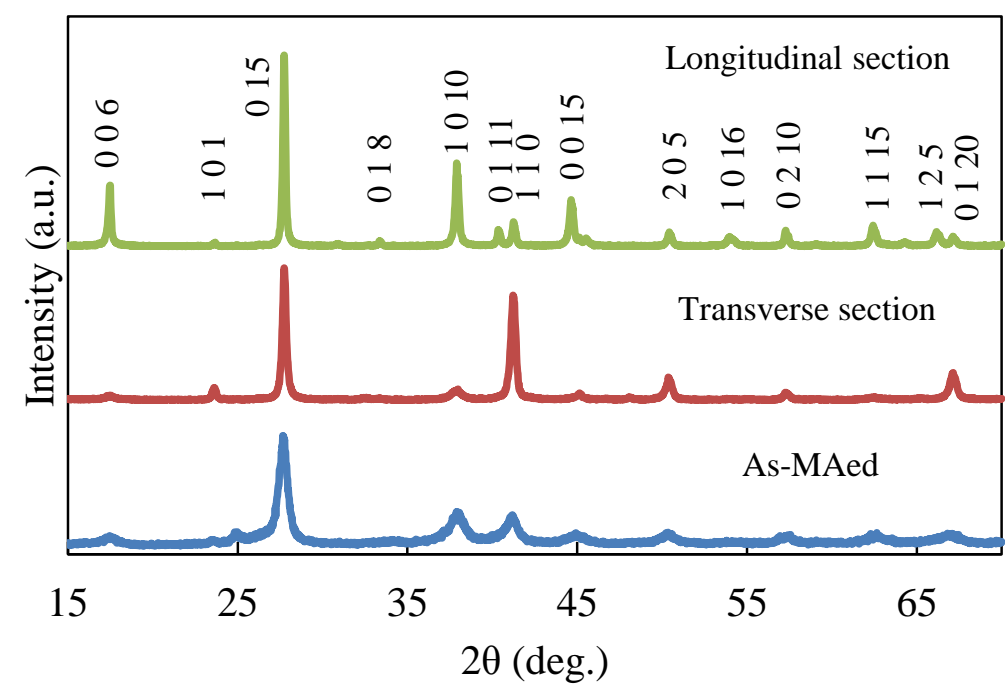


Figure 7

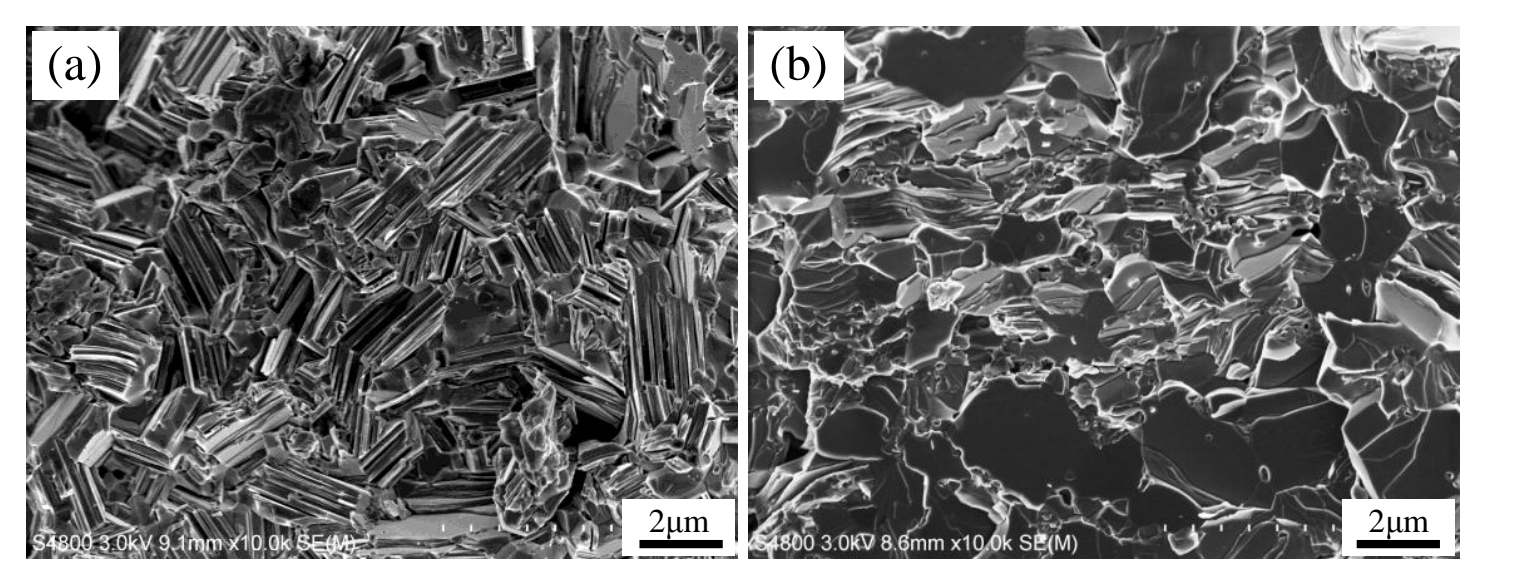

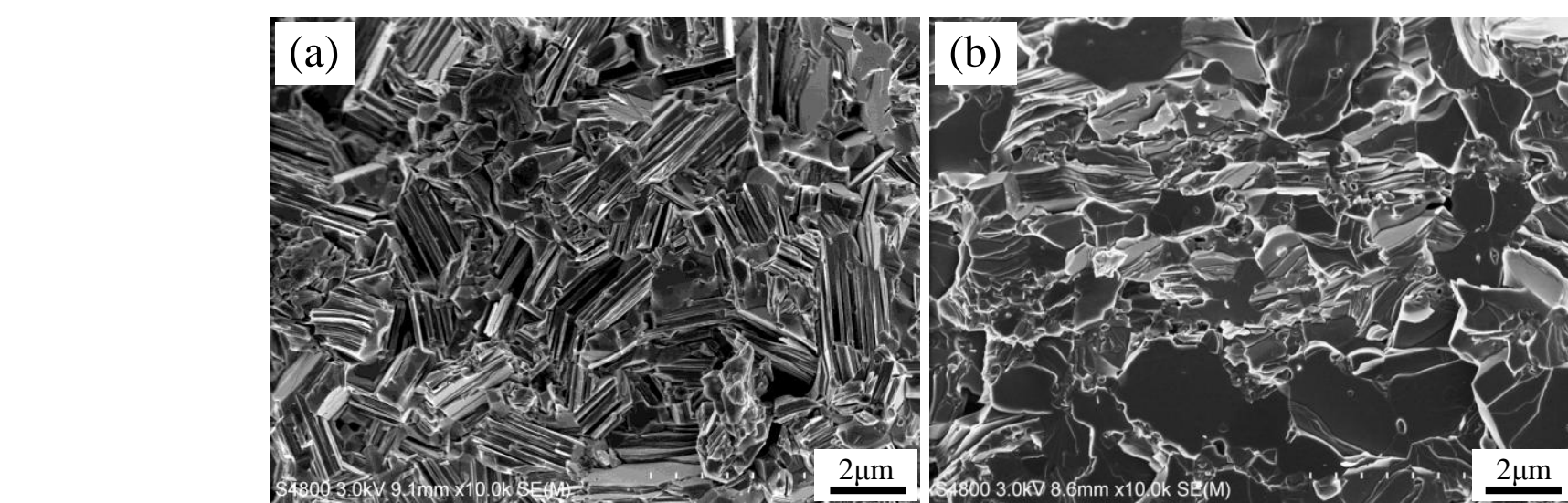

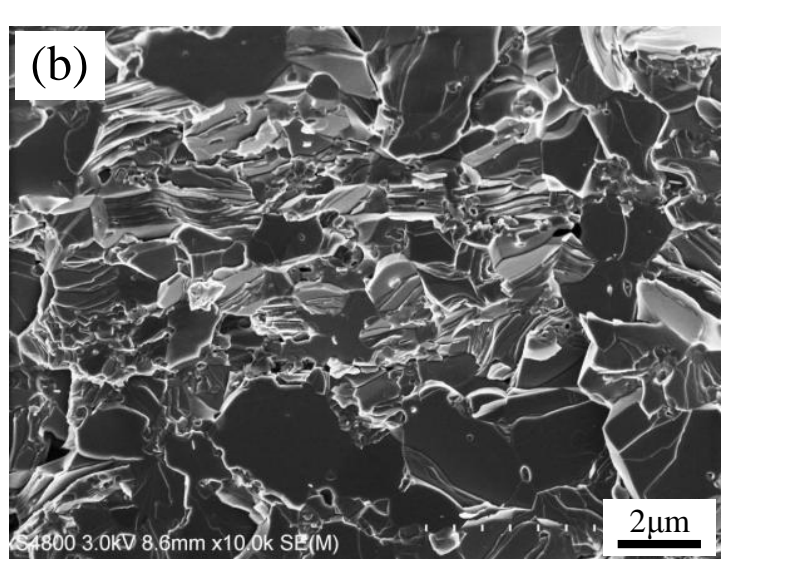


Figure 9

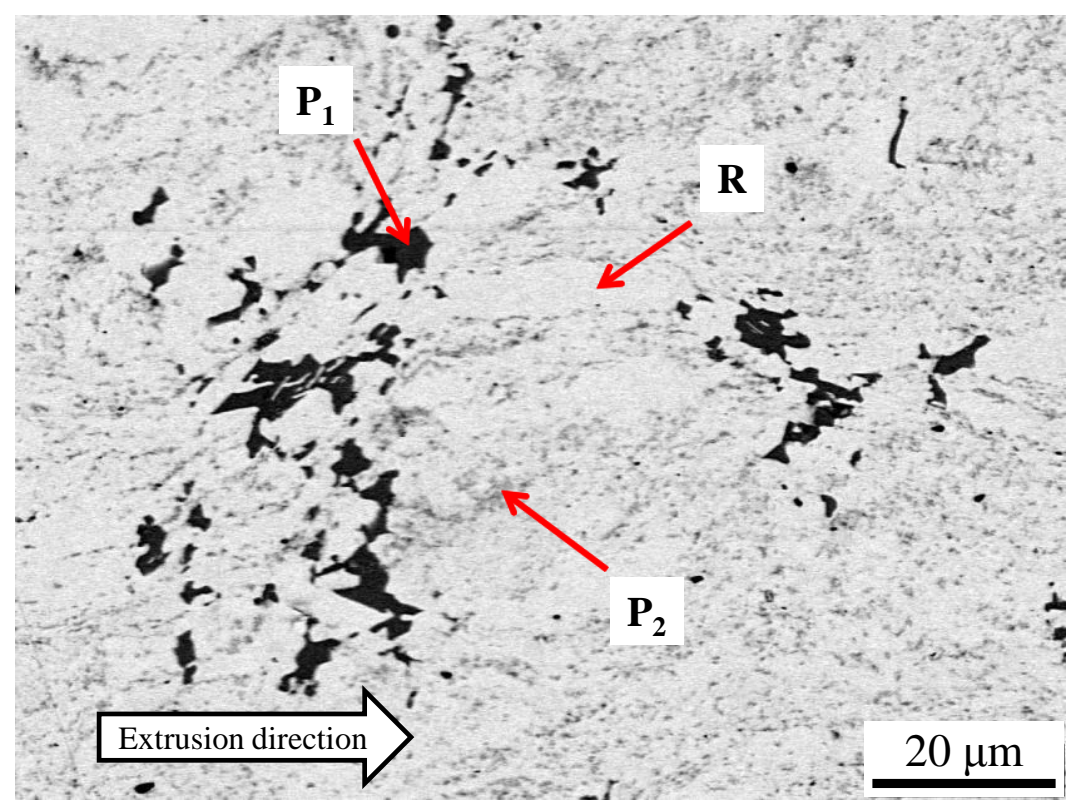


Figure 10

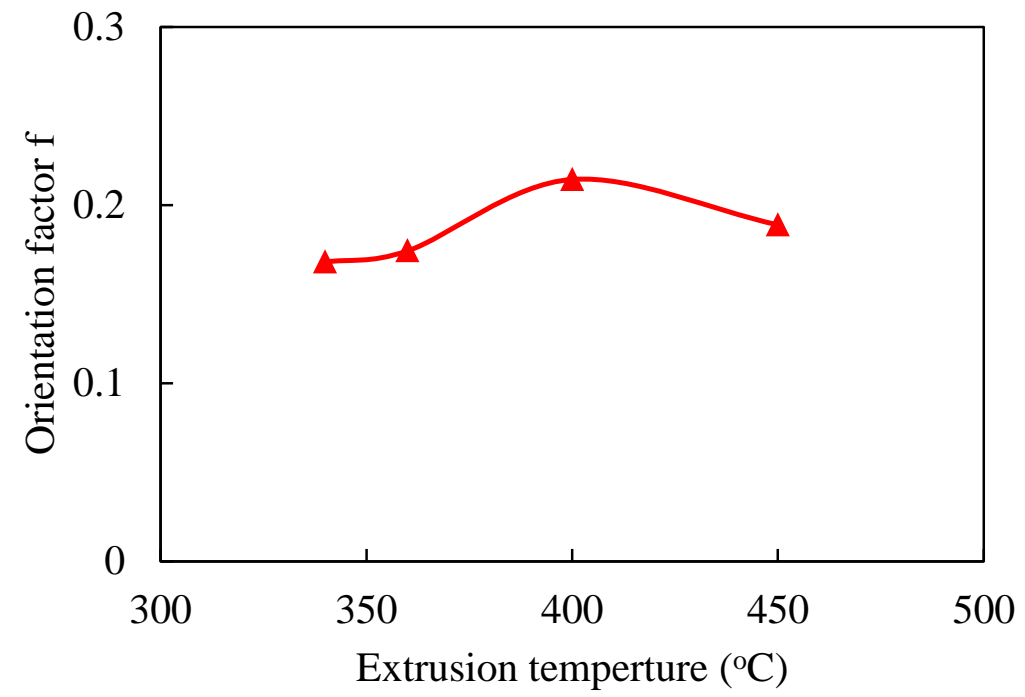


Figure 11

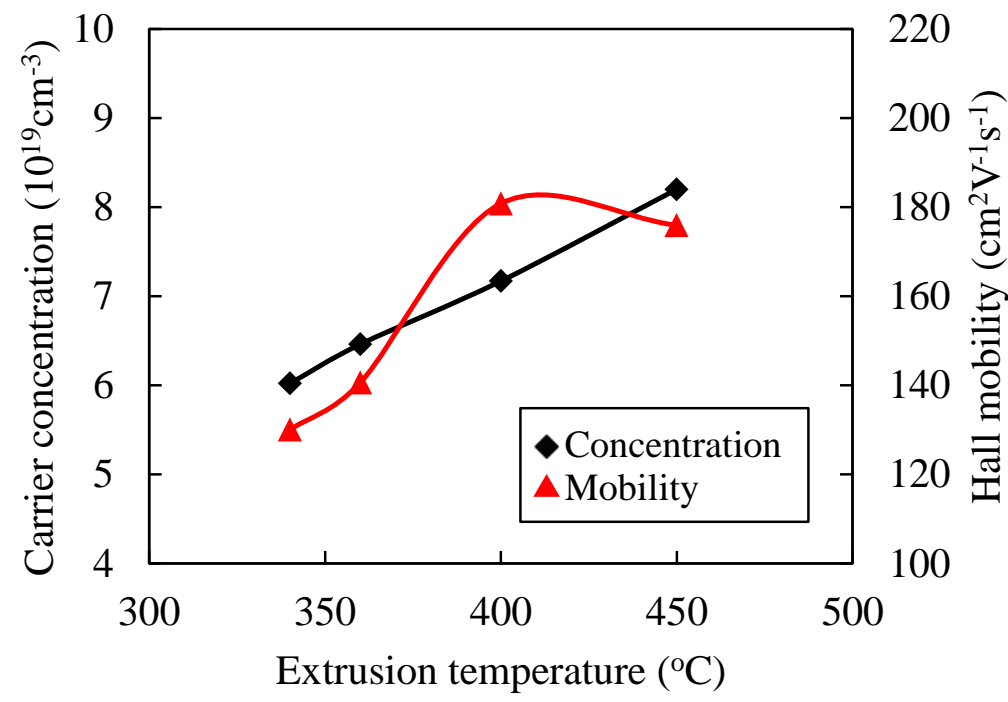




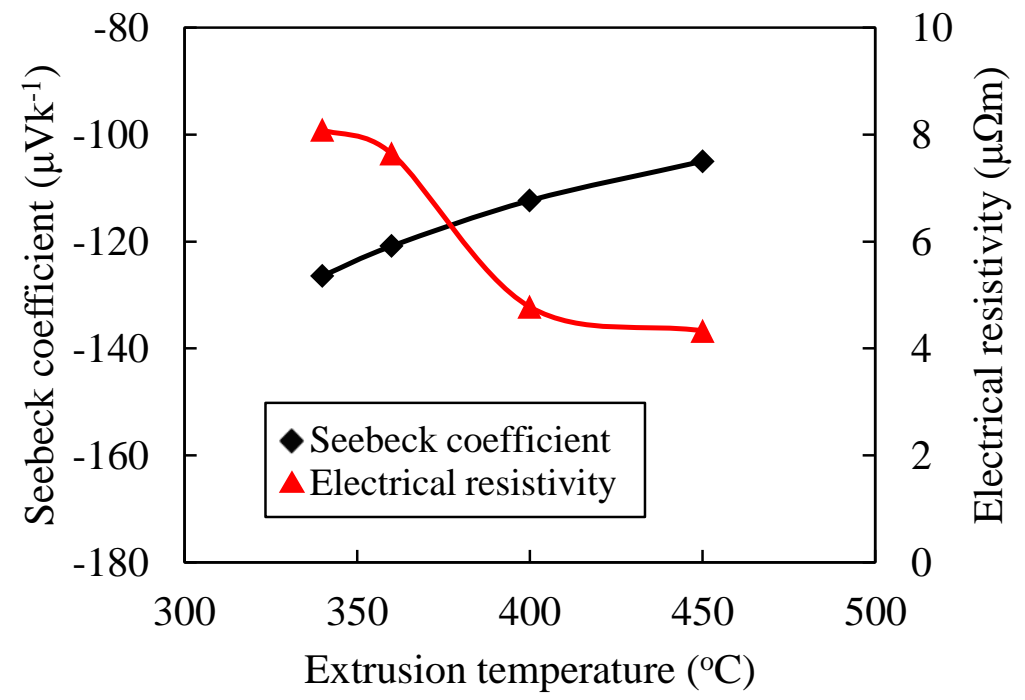




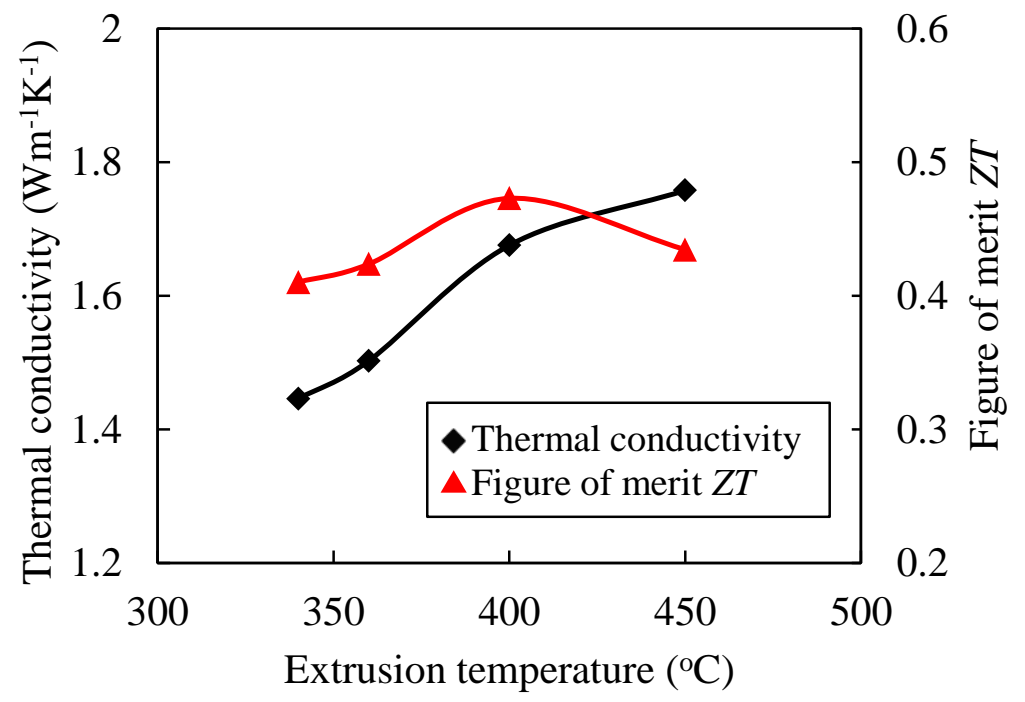


Figure 14

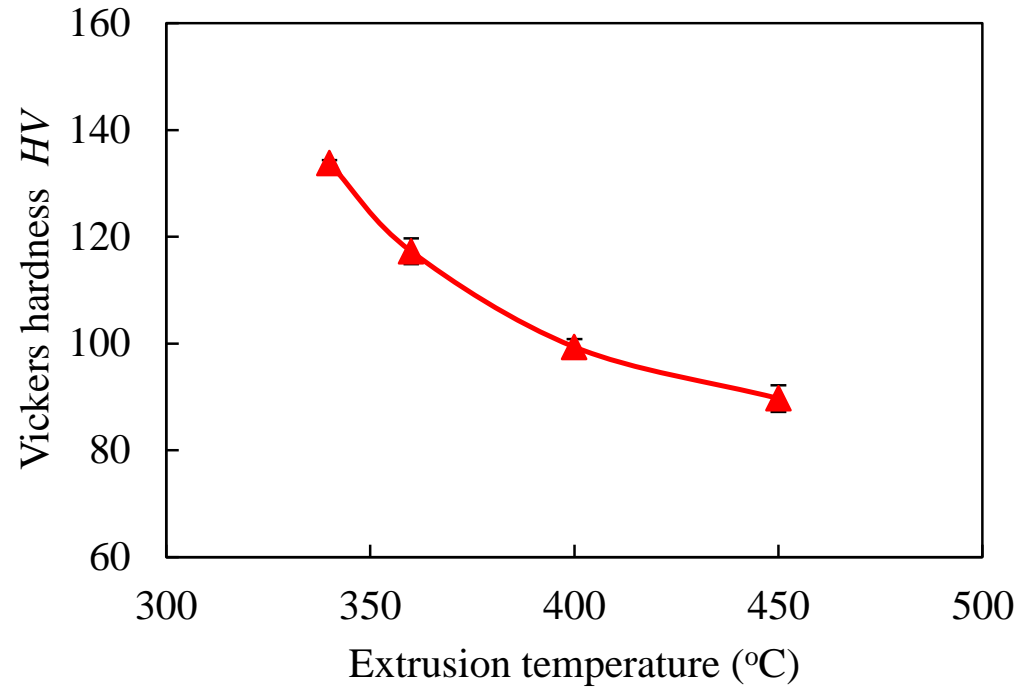

